\title{
EFEITOS DA TEMPERATURA DO AR, LINHAGEM E PERÍODO DO DIA NAS FREQÜÊNCIAS DE OCORRÊNCIAS E TEMPOS DE EXPRESSÃO COMPORTAMENTAL DE MATRIZES PESADAS ${ }^{1}$
}

\author{
DANILO F. PEREIRA ${ }^{2}$, DOUGLAS D. SALGADO ${ }^{3}$, IRENILZA A. NÄÄS \\ NÁRIMA L. J. PENHA ${ }^{5}$, CAMILA A. BIGHI ${ }^{6}$
}

\begin{abstract}
RESUMO: Ajustes de comportamento podem ocorrer rapidamente e a custo menor do que os ajustes fisiológicos. Considerando o comportamento social, é sugestivo que a freqüência e a intensidade de interações agressivas, o total de coesão social e a extensão de vícios sociais possam ser utilizados para avaliação de bem-estar. Esta pesquisa apresenta uma análise das interações entre os fatores experimentais, como temperatura, linhagem e período do dia, nos comportamentos de matrizes pesadas alojadas em câmara climática, buscando evidenciar as diferentes reações das aves submetidas a distintas condições ambientais. Os resultados encontrados mostraram diferenças significativas entre os comportamentos expressos pelas diferentes linhagens, reforçando a necessidade do monitoramento em tempo real do bem-estar de matrizes pesadas em alojamentos comerciais, dada a complexidade com que as variáveis ambientais interferem no bem-estar. A pesquisa permitiu concluir também que a avaliação do bem-estar de matrizes pesadas deve considerar o período do dia na observação dos comportamentos.
\end{abstract}

PALAVRAS-CHAVE: bem-estar animal, interações, suporte à tomada de decisão.

\section{EFFECT OF AIR TEMPERATURE, GENETIC AND PERIOD OF THE DAY IN THE FREQUENCIES OF OCCURRENCES AND LENGTH OF TIME OF BEHAVIORAL EXPRESSION OF BROILER BREEDERS}

\begin{abstract}
Behavioral adjustments may occur fast and with less cost than the physiological adaptations. Considering the social behavior is suggestive that the frequency and the intensity of aggressive interactions, the total social cohesion and the extent of vicious attitudes may be used to evaluate welfare. This research presents an analysis of the interactions between the experimental factors such as temperature, genetic and time of the day in the behavior of female broiler breeders under controlled environment in a climatic chamber in order to enhance the different reaction of the birds facing distinct environmental conditions. The results showed significant differences between the behaviors expressed by the studied genetics presenting the need of monitoring them in real-time in order to predict their welfare in commercial housing, due to the complexity of the environmental variables that interfere in the well being process. The research also concluded that the welfare evaluation of female broiler breeders needs to consider the time of the day during the observation of the behaviors.
\end{abstract}

KEYWORDS: animal welfare, interactions, decision making support.

\section{INTRODUÇÃO}

Pouco conhecida é a maneira como as diferentes aves respondem a diferentes estados de sofrimento e estresse. Durante o estresse térmico, as aves alteram seu comportamento para auxiliar na manutenção da temperatura corporal dentro de limites normais. Ajustes de comportamento podem ocorrer rapidamente e a custo menor do que os ajustes fisiológicos. CAMPOS (2000)

\footnotetext{
${ }^{1}$ Extraído da tese de Doutorado do primeiro autor.

${ }^{2}$ Eng ${ }^{o}$ Agrícola, Prof. Doutor, Faculdade de Administração, UNESP - Câmpus Experimental de Tupã - SP, Fone: (0XX14) 34044200, danilo@tupa.unesp.br

${ }^{3}$ Estatístico, Doutorando, Faculdade de Engenharia Agrícola - UNICAMP, Campinas - SP.

${ }^{4}$ Eng $^{\mathrm{a}}$ Civil, Professora Titular, Faculdade de Engenharia Agrícola, UNICAMP, Campinas - SP.

${ }^{5}$ Graduanda, Faculdade de Administração, UNESP - Câmpus Experimental de Tupã - SP.

${ }^{6}$ Graduanda, Faculdade de Administração, UNESP - Câmpus de Jaboticabal - SP.

Recebido pelo Conselho Editorial em: 8-11-2006
}

Aprovado pelo Conselho Editorial em: 19-7-2007 
considera fundamental a identificação de fatores responsáveis pelo bem-estar das aves, uma vez que a exploração avícola atual é, fundamentalmente, baseada na mudança de comportamento das mesmas. DUNCAN \& MENCH (1993) propuseram que o comportamento possa ser utilizado para identificar estados de sofrimento do animal e, em particular, os estados de febre, frustração e dor em vários sistemas de produção. Considerando o comportamento social, é sugestivo que a freqüência e a intensidade de interações agressivas, o total de coesão social e a extensão de vícios sociais possam ser utilizados para avaliação de bem-estar.

Conhecer e garantir o bem-estar das aves no sistema de criação sempre foi importante, pois esse afeta diretamente a produção das aves. Considerando as pequenas margens de lucro do produtor, o bem-estar das aves pode significar a viabilidade econômica no negócio. Assim, a construção de modelos de estimativa do bem-estar que auxilie no suporte à decisão na gestão de aviários, que utilize parâmetros inerentes às aves, em tempo real, torna-se cada vez mais necessário para o sucesso e a sustentabilidade da avicultura nacional.

Ao encontro das demandas, diversos autores vêm pesquisando o bem-estar animal, utilizando tecnologias complexas, devido à importância desse tema na atualidade (MARÍA et al., 2004; MARCHANT et al., 2001; PEREIRA, 2003). Como as variáveis fisiológicas são difíceis de serem medidas em condições de campo, os estudos do comportamento têm-se mostrado mais viáveis para inferir sobre os níveis de bem-estar de aves alojadas. PETTIT-RILEY \& ESTEVEZ (2001) estudaram os efeitos do crescimento e do acesso a poleiros no comportamento agressivo de frangos de corte, observando que o comportamento agressivo aumenta de acordo com o crescimento e a densidade de aves no poleiro, devido ao aumento da competição (PETTIT-RILEY et al., 2002). ESTEVEZ et al. (2003) observaram os comportamentos de galinhas poedeiras em vários grupos com número de aves diferentes, mantendo-se a densidade. A dinâmica dos comportamentos agressivos foi influenciada pelo contexto da competição pelo alimento e o tamanho do grupo influenciou inversamente na média de interações agressivas. Nesse contexto, é esperado que a restrição alimentar adotada neste experimento afete os comportamentos agressivos das matrizes.

Diversos autores têm estudado comparativamente os comportamentos afetados pelo ambiente (KEER-KEER et al., 1996; McGARY et al., 2003), mostrando diferenças importantes nas respostas comportamentais entre as linhagens. CHENG \& MUIR (2005) afirmam que as linhagens provenientes de diferentes seleções genéticas apresentam respostas fisiológicas de homeostase diferentes, afetando a longevidade e a produção em função do ambiente de produção. A correta escolha da linhagem para o ambiente produtivo possível de ser oferecido é muito importante para que se alcancem altos níveis de produtividade e, portanto, estudos do bem-estar comparativos entre linhagens são fundamentais para subsidiar a escolha da linhagem pelo produtor.

Este trabalho teve o objetivo de demonstrar que os fatores experimentais temperatura, linhagem e período do dia afetam os comportamentos das matrizes pesadas, evidenciando a complexidade dos efeitos desses fatores no bem-estar das aves e levanta as seguintes hipóteses: 1) as linhagens possuem diferentes resistências ao ambiente térmico e, portanto, expressam diferentemente os comportamentos; 2) a presença do alimento em parte do dia, decorrente da restrição alimentar, afeta os comportamentos das matrizes, e 3) os fatores experimentais combinados (interações ${ }^{\mathrm{a}}$ ) possibilitam melhor compreensão dos estados de bem-estar das matrizes pesadas.

\section{MATERIAL E MÉTODOS}

O experimento foi conduzido durante julho-2005 e agosto-2005, em câmara climática, localizada na Faculdade de Engenharia Agrícola da UNICAMP, em Campinas - SP, na latitude $22^{\circ} 53^{\prime} \mathrm{S}$ e longitude $47^{\circ} 03^{\prime} \mathrm{W}$. Foram verificadas respostas comportamentais em função do

\footnotetext{
a Interação é quando os efeitos de dois ou mais fatores de variação são ditos não-aditivos, ou seja, quando na associação de um ou mais desses fatores, em vez de se somarem, esses efeitos se multiplicam, de tal forma que o efeito resultante é ampliado (quando o fator multiplicativo é maior que 1), ou reduzido (quando esse fator é menor que 1).
} 
ambiente e correlações importantes entre os comportamentos e a produção. O estudo foi realizado durante nove dias, simulando onda de calor para o mesmo grupo de matrizes pesadas.

\section{Matrizes pesadas}

Dez matrizes pesadas e dois galos das linhagens Cobb-500, Hybro-PG e Ross 308, com idades de 26; 29 e 32 semanas, respectivamente, próximas ao pico de produção, foram alojados ao mesmo tempo em três boxes dentro de uma câmara climática, conforme Figura 1, totalizando 30 matrizes e seis galos. As densidades de aves por $\mathrm{m}^{2}$ e matrizes/galos utilizadas neste experimento foram estabelecidas para serem as mais próximas das densidades observadas nas granjas.
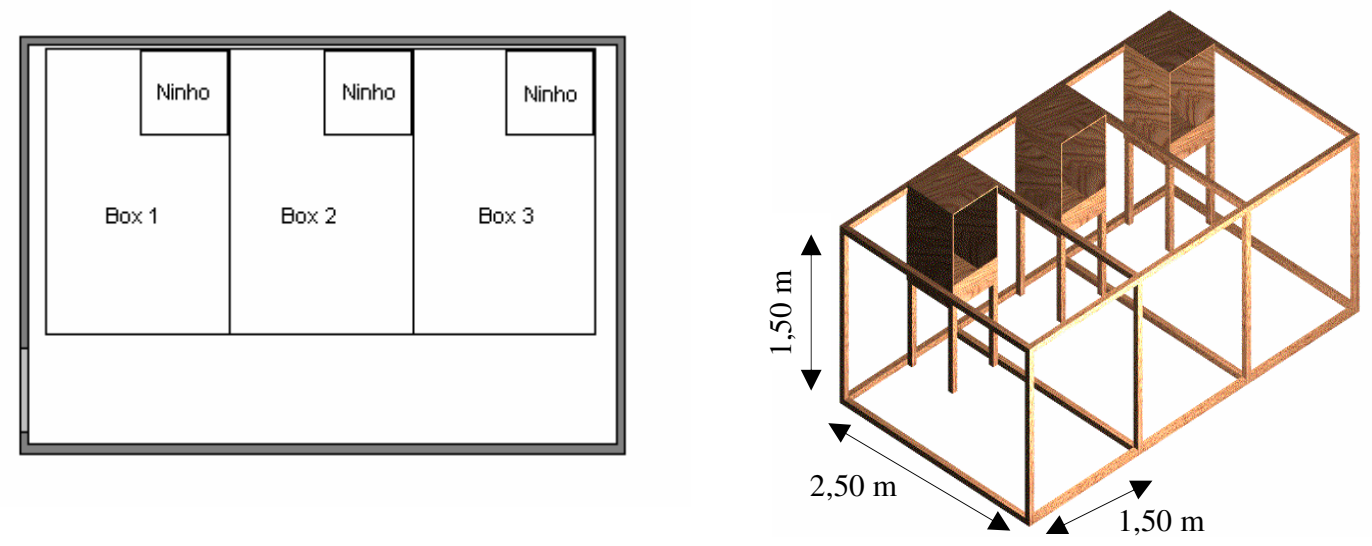

FIGURA 1. Esquema da construção e disposição dos boxes dentro da câmara climática.

\section{Condições ambientais}

As aves foram expostas a três condições de temperatura controlada: $26,3{ }^{\circ} \mathrm{C} ; 29,5{ }^{\circ} \mathrm{C}$ e $33,0{ }^{\circ} \mathrm{C}$, com umidade relativa de $75 \% \pm 5 \%$, sendo as aves expostas a cada condição térmica por período de três dias seguidos. A variação da temperatura dentro da câmara climática foi de $\pm 1{ }^{\circ} \mathrm{C}$, medida por termoigrômetros da Hobo ${ }^{\circledR}$, instalados no interior e no centro de cada box. As mesmas aves foram expostas às três condições de temperatura descritas acima, sem intervalos, simulando onda de calor nesses animais.

\section{Arraçoamento}

Cada linhagem recebeu a formulação de ração já fornecida na granja de origem, de modo que a ração não caracterizou tratamento experimental, mantendo-se a restrição alimentar adotada nas granjas. A ração foi administrada apenas uma vez ao dia, durante a manhã, na quantidade fornecida para o lote de origem na granja, de acordo com o plano de produção.

\section{Período pré-experimental}

Em cada box, foi alojado um grupo de matrizes de uma determinada linhagem, constituído de dez matrizes e dois galos. Todas as matrizes foram identificadas eletronicamente com um transponder identificador da Trovan ${ }^{\circledR}$, implantado na coxa, conforme preconizado por PEREIRA (2003). Para minimizar o estresse do transporte e do manejo de entrada, as aves foram submetidas à condição de conforto com temperatura do ar de $24{ }^{\circ} \mathrm{C}$ e umidade relativa de $75 \%$, dentro da câmara climática, durante três dias. Após esse período, a temperatura da câmara climática foi elevada até $26,3{ }^{\circ} \mathrm{C}$ e iniciou-se o monitoramento dos comportamentos.

\section{Programa de luz}

Como cada linhagem foi trazida de galpões com programas de luz diferentes, adotou-se o programa de maior exposição à luz dentre as linhagens selecionadas para o experimento, ou seja, $14 \mathrm{~h}$ de luz e $10 \mathrm{~h}$ de escuro, por recomendação das próprias granjas que cederam as aves. 


\section{Monitoramento dos comportamentos}

A observação dos comportamentos em destaque mostrados na Tabela 1 deu-se por meio de antenas de identificação eletrônica instaladas no ninho e no bebedouro de cada box, conforme mostra a Figura 2, monitorando, assim, os comportamentos de uso desses locais; os demais comportamentos foram monitorados por meio de câmeras de vídeo policromáticas instaladas no teto da câmara climática, uma sobre cada box.

TABELA 1. Etograma dos comportamentos observados.

\begin{tabular}{ll}
\hline Comportamento & Descrição \\
\hline Abrir asas & Movimento em que a matriz bate as duas asas. \\
\hline Arrepiar penas & Ação de arrepiar e sacudir todas as penas do corpo. \\
\hline Beber água & Ato em que a matriz se posiciona na frente do bebedouro e bebe água. \\
\hline Bebedouro* & $\begin{array}{l}\text { Situação em que a matriz se encontra no bebedouro, independentemente do ato } \\
\text { de beber água. }\end{array}$ \\
\hline Bicar & $\begin{array}{l}\text { Ação de a matriz bicar qualquer parte do corpo de outra matriz de forma } \\
\text { agressiva. }\end{array}$ \\
\hline Ciscar & $\begin{array}{l}\text { Movimento de arrastar a cama para trás com as patas e "mexer" a cama com o } \\
\text { bico. }\end{array}$ \\
\hline Deitar & Ato da matriz de ficar sentada ou deitada sobre a cama. \\
\hline Espojar & Banho realizado pela matriz utilizando o substrato da cama. \\
\hline Espreguiçar & Ato em que a matriz estica uma asa e uma perna do mesmo hemisfério do corpo. \\
\hline Limpar penas & $\begin{array}{l}\text { Ato em que a matriz arruma as penas com o bico, induzindo a liberação de óleos } \\
\text { nas glândulas encontradas na base das penas. }\end{array}$ \\
\hline Ninho* & Situação em que a ave se encontra no ninho. \\
\hline * Comportamentos monitorados por meio da tecnologia de identificação eletrônica.
\end{tabular}

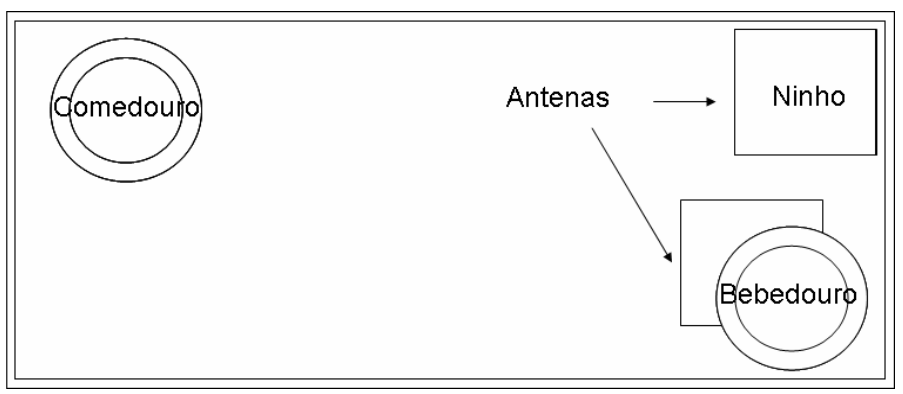

FIGURA 2. Esquema de disposição das antenas dentro do box.

Foram considerados dois períodos do dia para as observações dos comportamentos. O período da manhã, definido entre os horários das 6 e $12 \mathrm{~h}$, e o período da tarde, definido entre 12 e $18 \mathrm{~h}$. Nesses intervalos, foram gravadas amostras aleatórias de vídeo para a observação dos comportamentos, com 15 min de duração pela manhã e 15 min à tarde, de acordo com a metodologia preconizada por outros autores (BIZERAY et al., 2002; ESTEVEZ et al., 2003).

Os comportamentos foram observados quanto à freqüência de ocorrências e o tempo médio de duração. Por meio de análises exploratórias ${ }^{\mathrm{b}}$, buscou-se encontrar interações significativas entre os fatores experimentais para cada freqüência ou tempo de expressão dos comportamentos mostrados na Tabela 1. A verificação de interações entre os fatores experimentais nos comportamentos das matrizes pesadas contribui para o entendimento da dinâmica do bem-estar desses animais, direcionando as análises de estudos futuros que visem a modelar matematicamente o bem-estar para sistemas informatizados de suporte à decisão.

\footnotetext{
${ }^{\text {b }}$ Análise exploratória dos dados é o conjunto de ferramentas estatísticas gráficas e descritivas direcionado ao descobrimento de padrões nos dados.
} 


\section{RESULTADOS E DISCUSSÃO}

A busca de conhecimento sobre as respostas comportamentais de aves em função do ambiente criatório, para que sirva como base para sistemas de suporte à decisão na gestão do ambiente em aviários, passa a ser importante no cenário econômico e social atual. A identificação dos fatores influentes em cada comportamento e suas possíveis interações constituem passo fundamental para a construção desse conhecimento.

Verificaram-se, por meio da análise exploratória apresentada a seguir, as prováveis interações entre os fatores existentes (linhagem, temperatura e período) sobre as frequiências dos comportamentos observados. As figuras seguintes permitem observar as dependências entre os níveis dos fatores para cada comportamento observado, seja na freqüência de ocorrências, seja no tempo médio de expressão dos comportamentos, respectivamente. Os resultados observados nessas figuras são as representações gráficas dos resultados obtidos por meio das análises de variância, para $\alpha=5 \%$ de significância ${ }^{c}$.

As associações nas tendências (paralelismo) das médias mostradas para cada combinação de fatores indicam não-interação entre os fatores, ou seja, a tendência do comportamento frente aos níveis de um fator mantém-se semelhante, mesmo perante outro fator. Já a discordância (nãoparalelismo) indica a interação entre os fatores, ou seja, que a tendência do comportamento perante um fator depende do outro fator. Isso implica que, nos comportamentos nos quais forem observadas interações significativas entre os fatores controlados, esses fatores deverão ser considerados simultaneamente nos registros desses comportamentos para a construção de modelos de estimação do bem-estar. Esses gráficos de interações, além de mostrarem visualmente as dependências entre os fatores, mostram também as tendências de cada comportamento frente às combinações de variáveis explicativas, ou seja, observando as tangentes das retas, tem-se o aumento ou a diminuição das frequiências e tempos médios de expressão dos comportamentos frente aos diferentes níveis dos fatores experimentais combinados dois a dois. A seguir, são apresentados os gráficos discutidos de interações significativas obtidas para os comportamentos observados.

Observa-se na Figura 3, que, dado o não-paralelismo entre as médias das frequiências de ocorrências do comportamento beber água, houve interações entre os fatores experimentais linhagem e temperatura, denotando que esse comportamento tem suas médias de ocorrências afetadas por essa interação, ou seja, cada linhagem é afetada de maneira diferente pela temperatura, conforme também foi observado por CHENG \& MUIR (2005). As freqüências de beber água, sem considerar as diferentes linhagens, também apresentaram forte interação quando analisadas com a temperatura e o período do dia, ou seja, neste experimento, as médias gerais de todas as linhagens da frequiência de ocorrência de beber água aumentaram no período da tarde, quando a temperatura foi próxima da zona de conforto $\left(26,3^{\circ} \mathrm{C}\right)$; diminuíram quando estiveram próximas do limite da zona de termoneutralidade $\left(29,5^{\circ} \mathrm{C}\right)$, e não se alteraram quando estiveram acima do limite superior da zona de termoneutralidade $\left(33,0{ }^{\circ} \mathrm{C}\right)$. Porém, não se observaram interações entre as linhagens e os períodos do dia, ou seja, as linhagens, quando observadas separadamente, expressam, na média, freqüências de ocorrências de beber água semelhantes de manhã e à tarde.

$\mathrm{Na}$ Figura 4, também se observa forte interação entre os fatores linhagem e temperatura, porém as tendências de aumento do tempo de expressão do comportamento beber água é contrário quando comparado com a freqüência de ocorrências observadas para o mesmo comportamento (Figura 3), ou seja, enquanto uma linhagem aumenta a freqüência de expressão do comportamento beber água, essa diminui o tempo de permanência expressando esse comportamento. Observa-se, na Figura 4, que a linhagem ross expressa o comportamento de beber água diferente das outras duas linhagens quando se analisam conjuntamente os fatores linhagem e o período do dia. Essa

\footnotetext{
${ }^{c}$ Apesar de esses gráficos de interação não explicitarem numericamente os resultados do teste estatístico, como na análise de variância, os resultados neles observados e discutidos nesta pesquisa permitem que as análises sejam feitas se mantendo o mesmo rigor estatístico.
} 
verificação nos dados obtidos neste experimento adere aos resultados encontrados por McGARY et al. (2003), que também encontraram diferenças nas expressões dos comportamentos entre as linhagens.

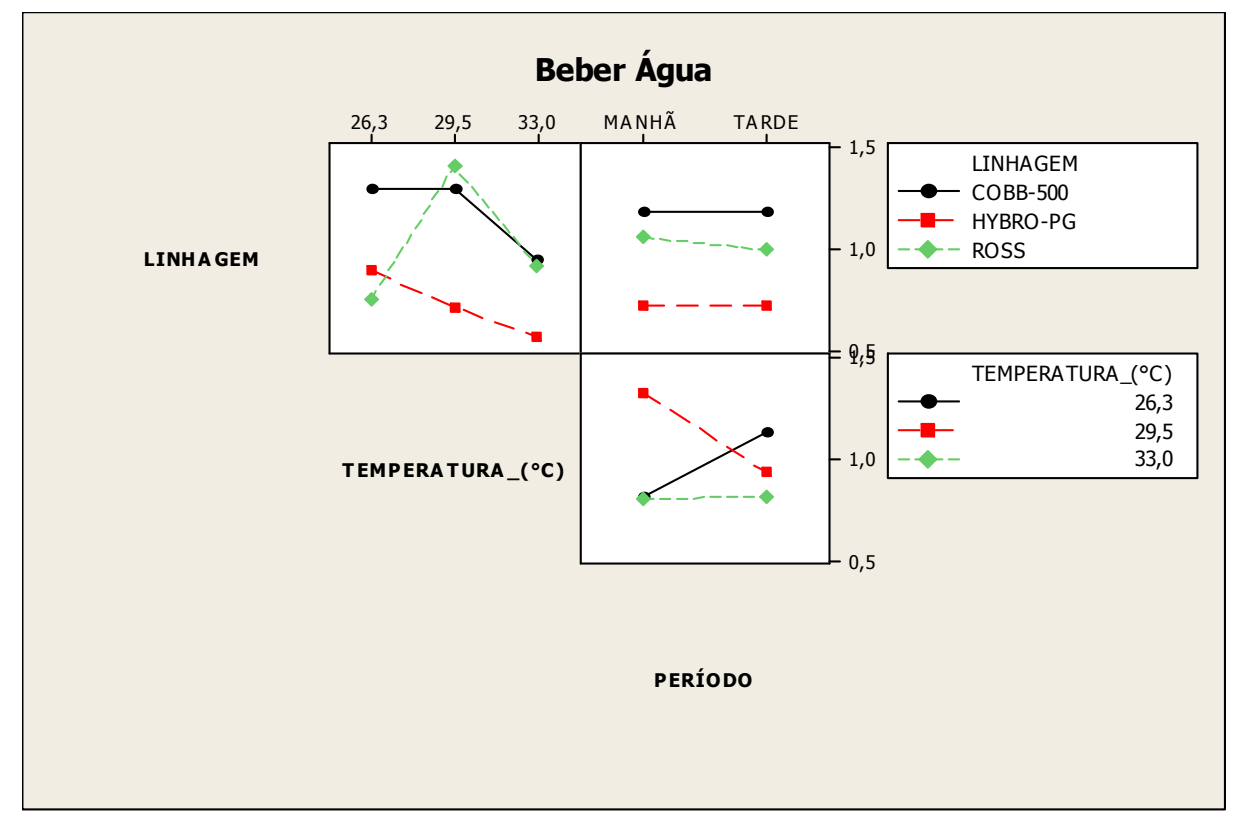

FIGURA 3. Interações entre linhagem, temperatura e período, duas a duas, perante a frequiência de ocorrência do comportamento "beber água".

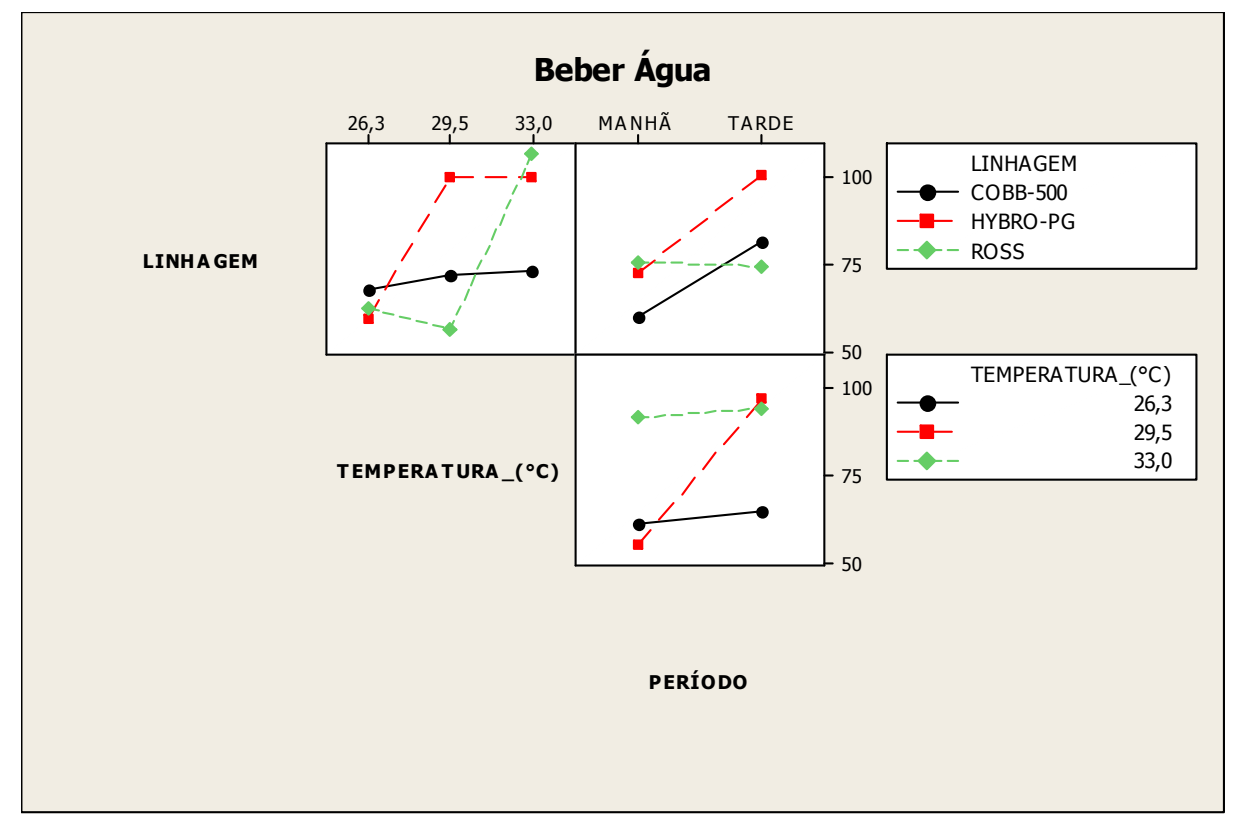

FIGURA 4. Interações entre linhagem, temperatura e período, duas a duas, perante a média do tempo de expressão do comportamento "beber água".

O comportamento arrepiar penas apresentou interações significativas entre os fatores experimentais apenas entre a linhagem e a temperatura, conforme se observa na Figura 5. KEERKEER et al. (1996) também observaram diferenças nas expressões comportamentais de frangos de corte entre linhagens. Esses resultados reforçam a necessidade de observar o comportamento de arrepiar penas considerando esta provável interação. 


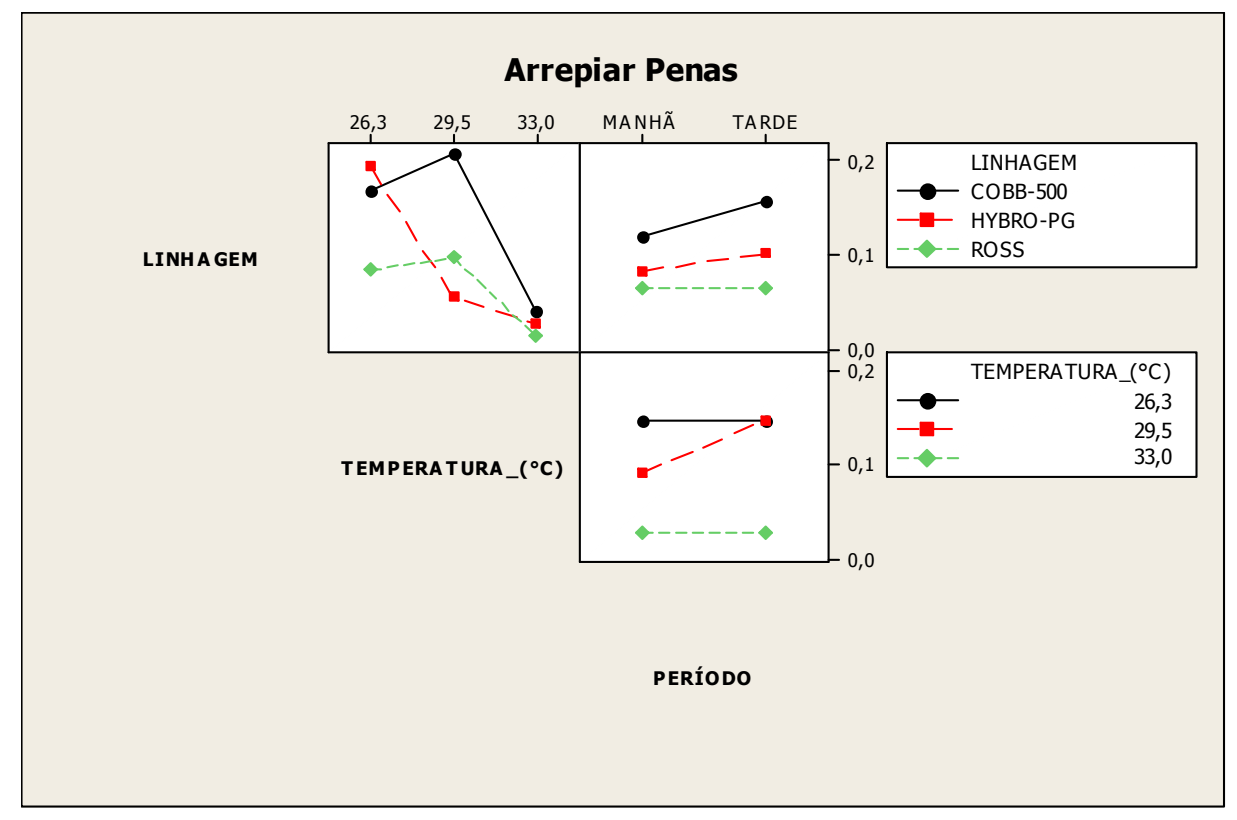

FIGURA 5. Interações entre linhagem, temperatura e período, duas a duas, perante a freqüência de ocorrência do comportamento "arrepiar penas".

Na Figura 6, observam-se interações entre todos os fatores experimentais para a freqüência de ocorrências do comportamento abrir asas. Na interação dos fatores linhagem e período do dia, é notório que cada linhagem apresenta tendência de frequiência média de expressão desse comportamento diferente uma da outra entre os períodos do dia. Enquanto a linhagem Cobb apresentou tendência de aumentar a freqüência de expressão de abrir asas no período da tarde, a linhagem ross tendeu a diminuir essa frequiência no mesmo período, e a linhagem Hybro mantevese constante. Essas diferenças significativas entre as linhagens são muito importantes de ressaltar quando se procuram evidências de estresse nos comportamentos. Considerando as três linhagens estudadas, não se pode afirmar que a variação de abrir asas reflita o mesmo comportamento para cada uma das linhagens aqui estudadas, ou seja, enquanto o aumento de abrir asas para uma linhagem pode significar perda de bem-estar, para a outra pode representar ganho.

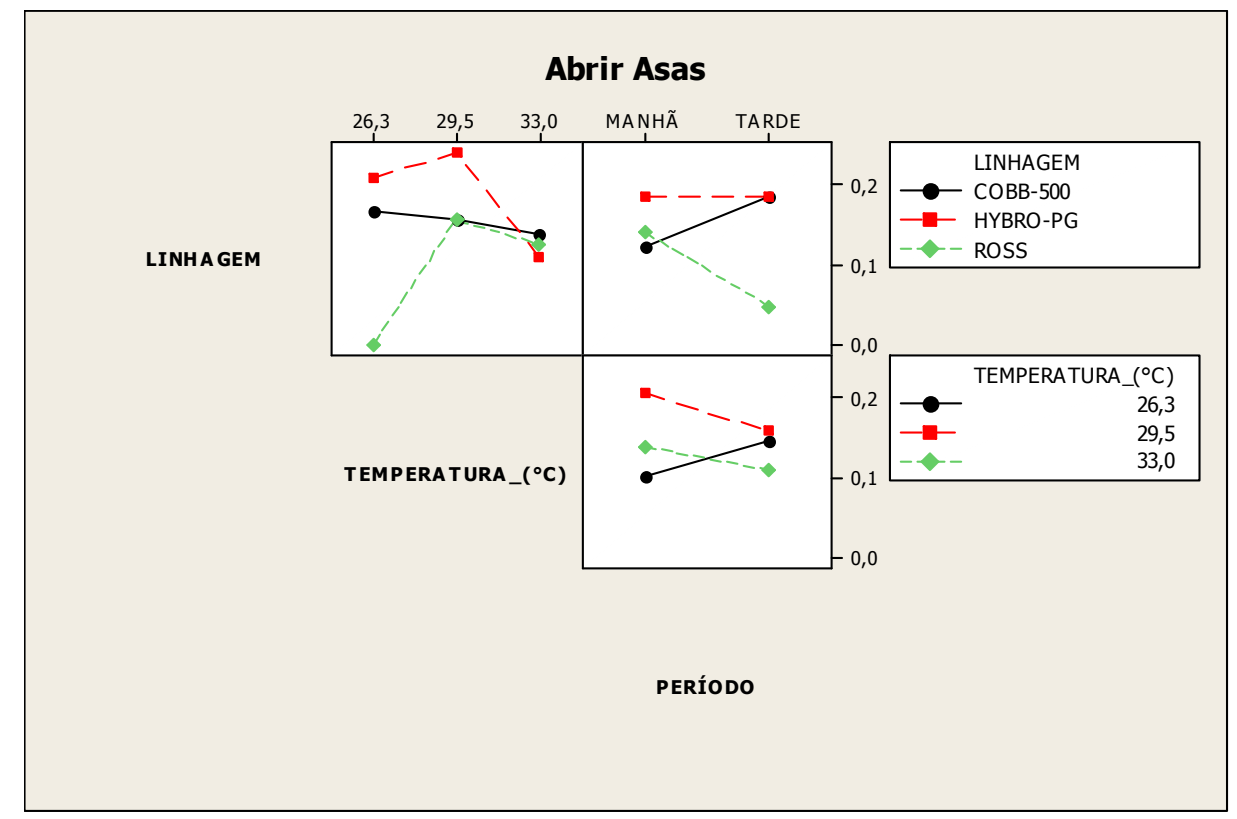

FIGURA 6. Interações entre linhagem, temperatura e período, duas a duas, perante a frequiência de ocorrência do comportamento "abrir asas". 
Assim como foi observado na Figura 6, a interação linhagem e período do dia também foi observada no comportamento ciscar, mostrado na Figura 7. Nessa interação, pode-se afirmar que a presença do alimento no período da manhã afetou de maneira diferente cada linhagem. A Cobb mostrou-se mais disposta a ficar no comedouro durante a manhã, aproveitando-se da disponibilidade do alimento, e ciscou mais à tarde, provavelmente à procura de ração derrubada na cama. Já as matrizes da linhagem hybro ciscaram mais de manhã.

Observa-se também, na Figura 7, forte interação entre a linhagem e a temperatura, em que é notório que as linhagens Hybro e Cobb tiveram forte decréscimo nas médias de ocorrências desse comportamento quando a temperatura foi aumentada, enquanto a linhagem Ross não sofreu alteração. O mesmo pode ser dito para o tempo médio de expressão do ciscar (Figura 8), quando se observam as interações temperatura e linhagem. Porém, não se pode afirmar que houve interações entre os fatores linhagem e período, no qual se observa que todas as linhagens tiveram decréscimo do tempo em que permaneciam ciscando.

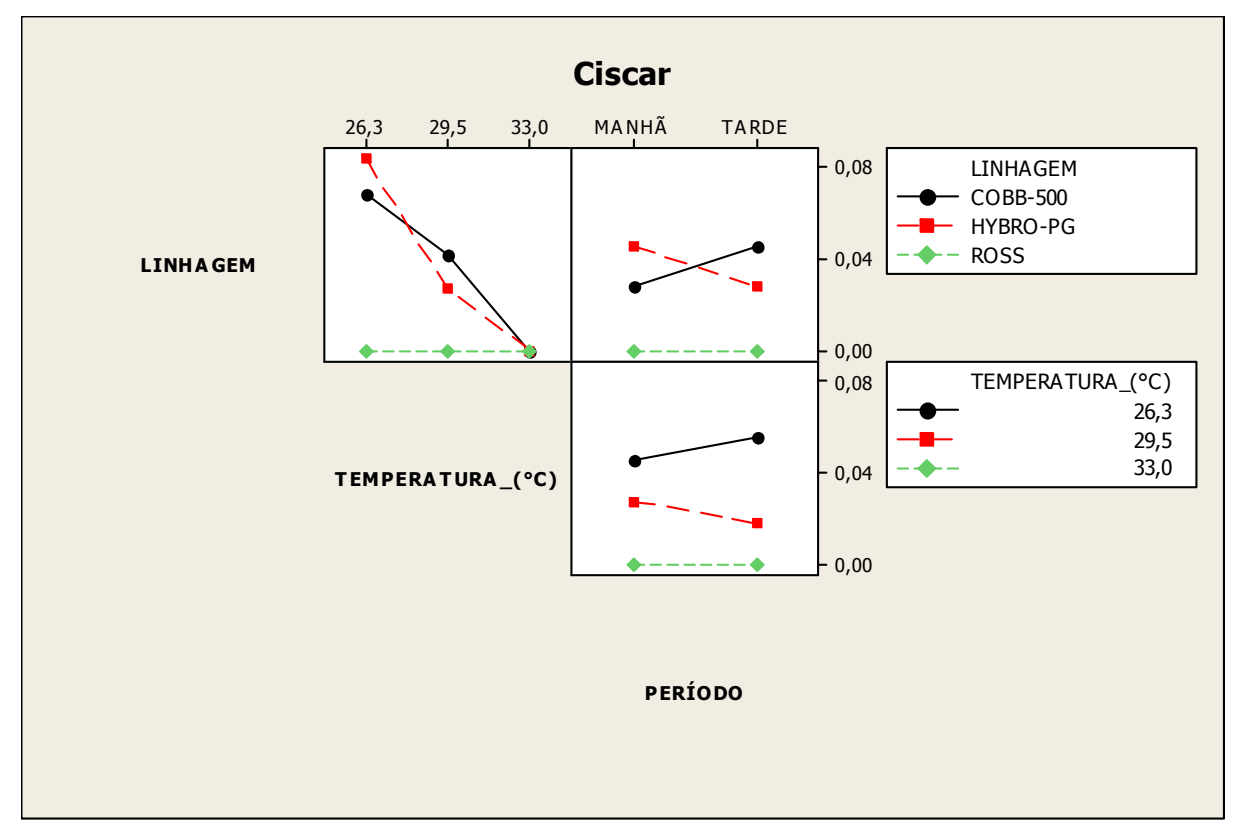

FIGURA 7. Interações entre linhagem, temperatura e período, duas a duas, perante a frequiência de ocorrência do comportamento "ciscar".

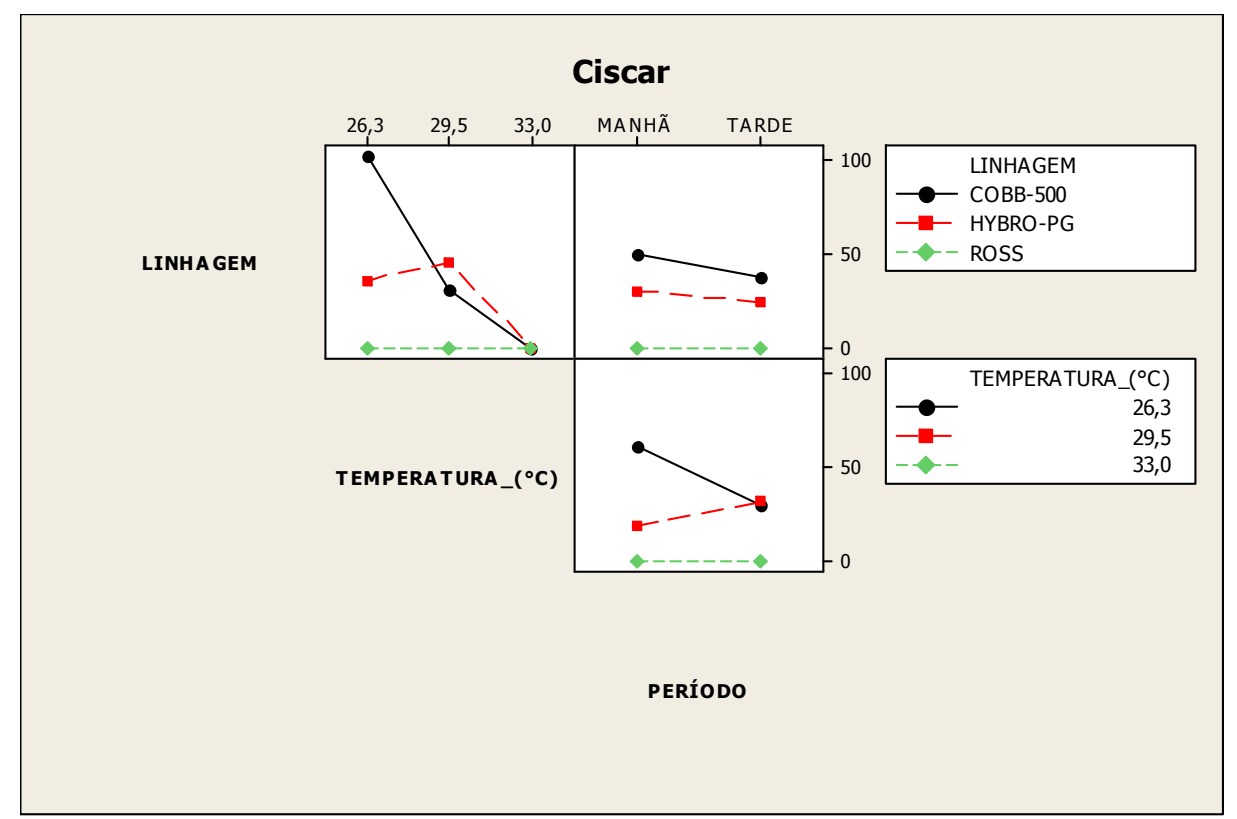

FIGURA 8. Interações entre linhagem, temperatura e período, duas a duas, perante a média do tempo de expressão do comportamento "ciscar". 
Quando comparadas as interações entre temperatura e período da freqüência observada e do tempo médio de ciscar, notam-se, em ambos os casos, interações entre os fatores (Figura 7 e Figura 8 ), porém, no caso da temperatura de $26,3{ }^{\circ} \mathrm{C}$, verifica-se que a freqüência de ciscar aumenta no período da tarde, e o tempo médio de expressão desse comportamento diminui para o mesmo período; para a temperatura de $29,5^{\circ} \mathrm{C}$, a freqüência de ocorrência diminui, e o tempo médio de expressão aumenta, comparados o período da manhã com o período da tarde; na temperatura de $33,0{ }^{\circ} \mathrm{C}$, verifica-se mudança nas tendências.

$\mathrm{Na}$ Figura 9, observa-se que a interação entre as variáveis explicativas linhagem e temperatura é a que mais se destaca. A frequiência de deitar da linhagem Ross diminui com o aumento da temperatura, enquanto a freqüência desse mesmo comportamento aumenta para a linhagem Cobb. MACARI et al. (2004) afirmam que as aves, submetidas a estresse térmico, diminuem as suas atividades físicas, conforme foi observado nas linhagens Cobb e Hybro. Já na Figura 10, observa-se que a interação entre a linhagem e o período, e a interação entre a temperatura e o período foram as mais significativas. Sem considerar a linhagem, observa-se que existe forte tendência de as médias do tempo de deitar caírem quando a temperatura estiver próxima da zona de conforto, enquanto, em temperaturas maiores, a tendência é o aumento do tempo do comportamento deitar.

Comparando-se a Figura 9 com a Figura 10, observa-se que a freqüência de deitar, para todas as temperaturas, diminui no período da tarde, o que permite dizer que, para temperaturas próximas ao limite superior da zona de termoneutralidade, observou-se que as matrizes pesadas diminuíram a frequiência de deitar; porém, o tempo médio em que ficaram deitadas aumentou, ou seja, diminuiu a atividade física, que corrobora os relatos de MACARI et al. (2004).

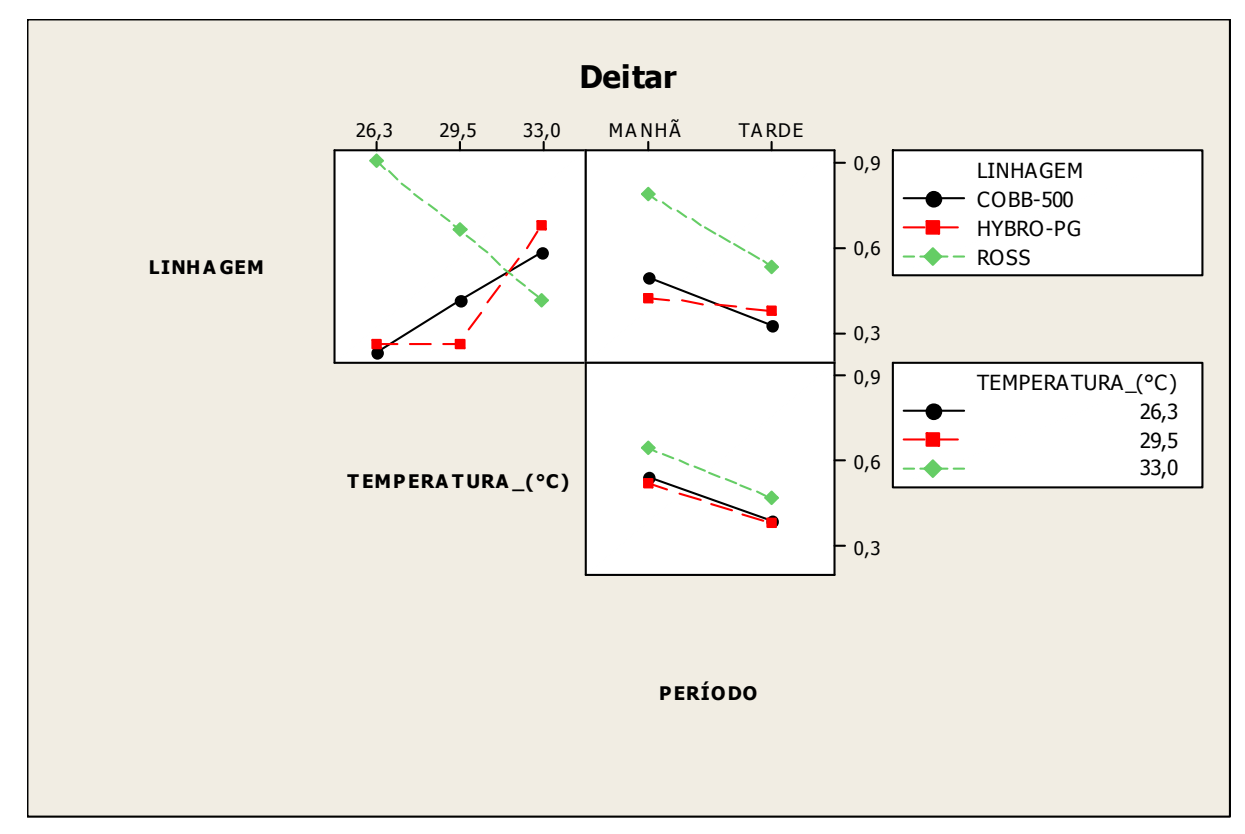

FIGURA 9. Interações entre linhagem, temperatura e período, duas a duas, perante a frequiência de ocorrência do comportamento "deitar". 


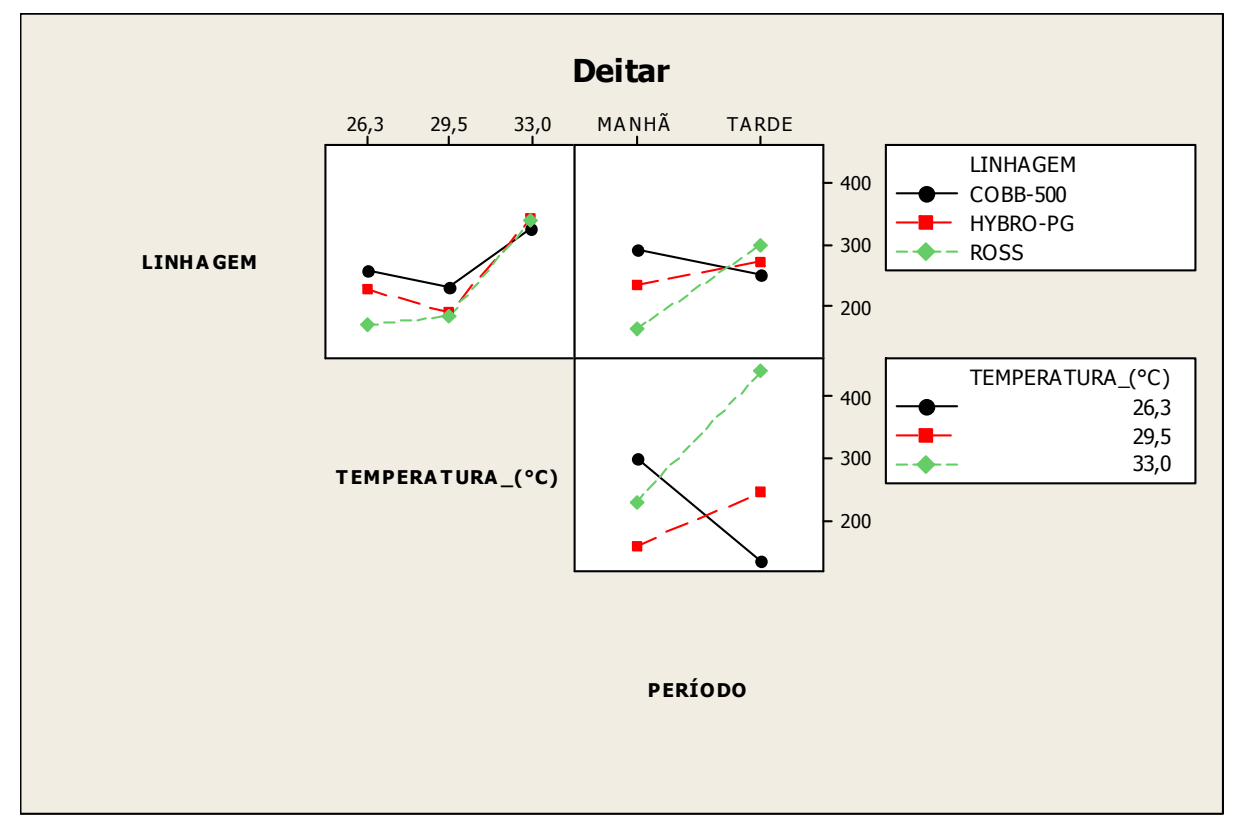

FIGURA 10. Interações entre linhagem, temperatura e período, duas a duas, perante a média do tempo de permanência no "bebedouro".

Ao encontro do que foi observado na Figura 9, em que a linhagem Ross teve sua freqüência observada de deitar diminuída em temperaturas maiores, observa-se, na Figura 11, no gráfico de interação da linhagem com a temperatura, que a Ross manteve durante todo o experimento frequiências de visitas ao bebedouro maiores que as outras linhagens, ou seja, a linhagem Ross visitou mais vezes esse local, provavelmente tentando favorecer-se do microclima gerado ao redor desse equipamento. Essa frequiência de uso foi aumentada quando a temperatura aumentou, mostrando que, de fato, a linhagem estava movimentando-se, diferentemente das outras linhagens.

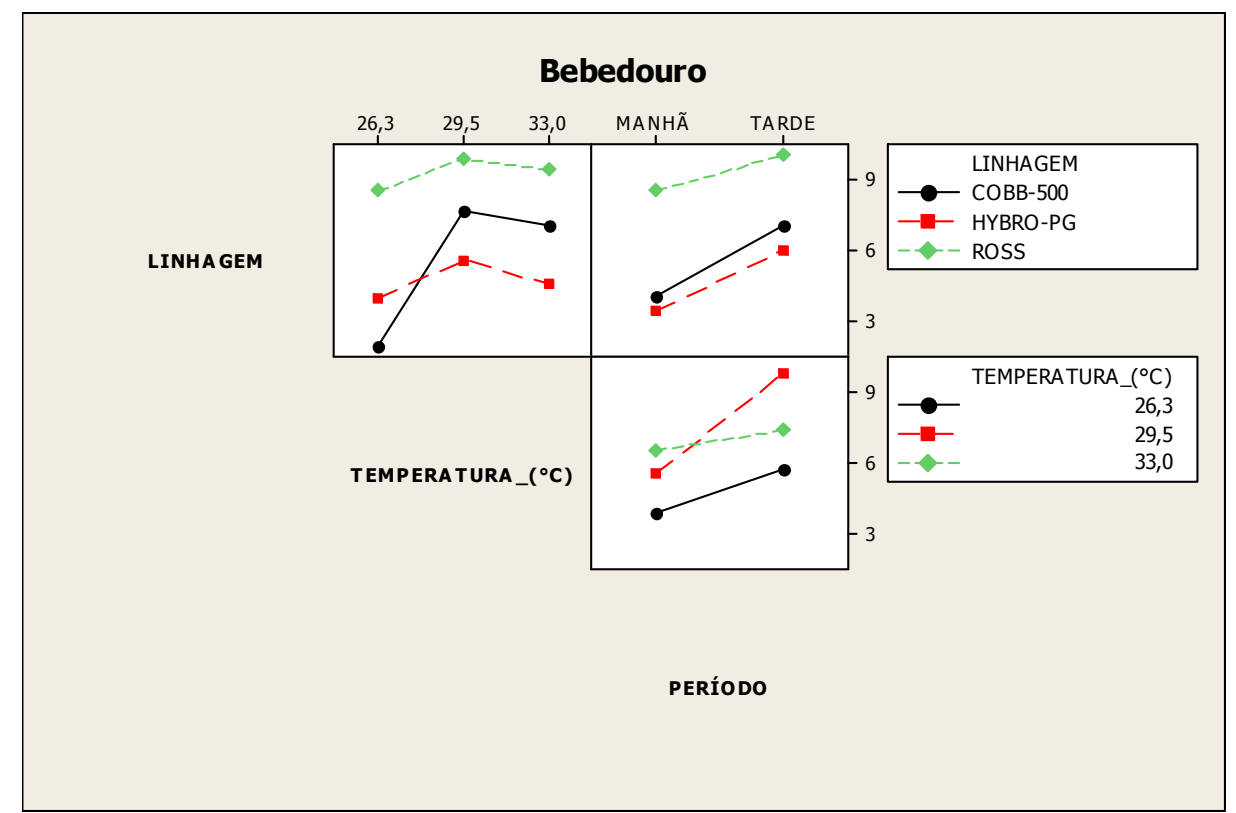

FIGURA 11. Interações entre linhagem, temperatura e período, duas a duas, perante a freqüência de ocorrência do comportamento "bebedouro". 
Observa-se, na Figura 12, que, apesar de o tempo médio de permanência no bebedouro da Ross ter aumentado com o aumento da temperatura ambiente, essa jamais foi superior ao tempo de permanência no bebedouro observado para a Cobb e, a partir da temperatura de $29,5^{\circ} \mathrm{C}$, foi ultrapassada pela linhagem Hybro, que apresentou aumento do tempo de permanência, nesse local, muito mais acentuado.

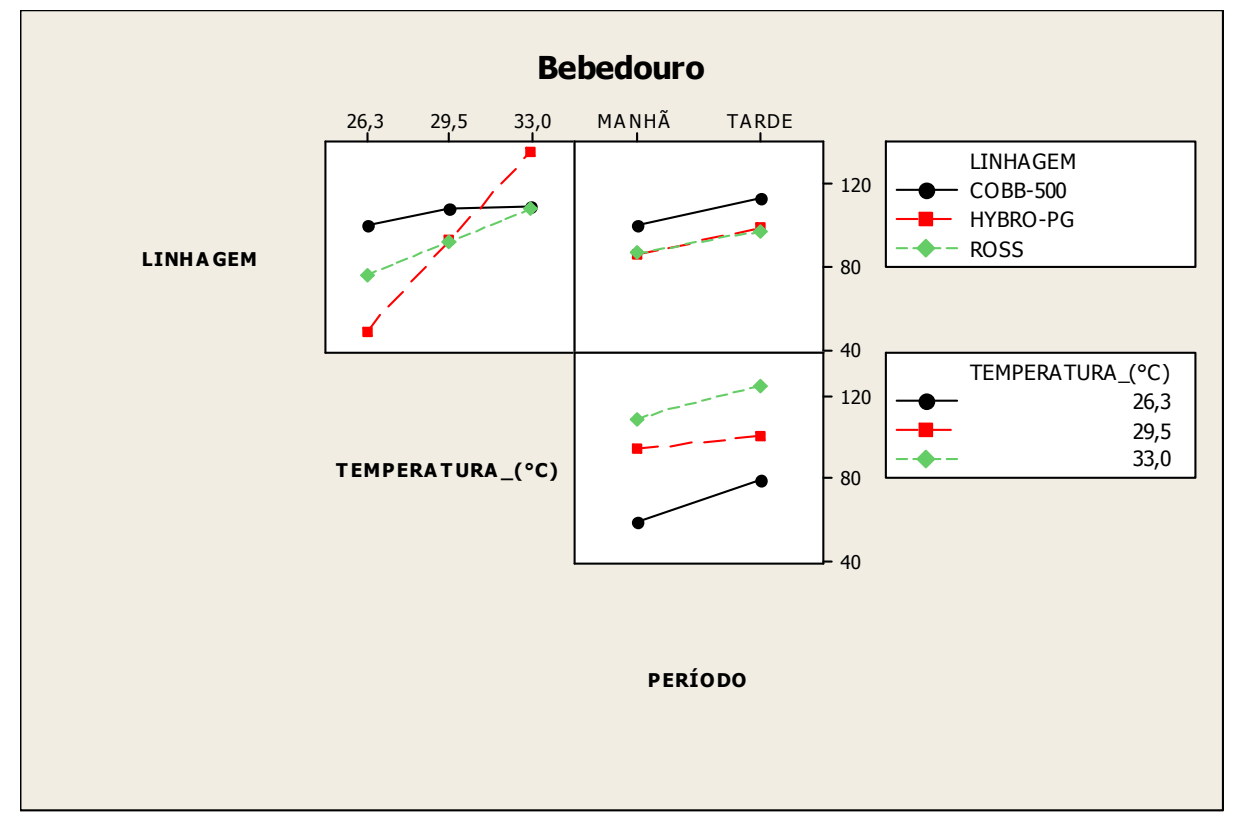

FIGURA 12. Interações entre linhagem, temperatura e período, duas a duas, perante a média do tempo de permanência no "bebedouro".

$\mathrm{Na}$ freqüência de ocorrências do comportamento espreguiçar, observa-se a importância das interações entre todas as variáveis explicativas, conforme se observa na Figura 13. O mesmo ocorre com as freqüências observadas do comportamento limpar penas, mostrado na Figura 14.

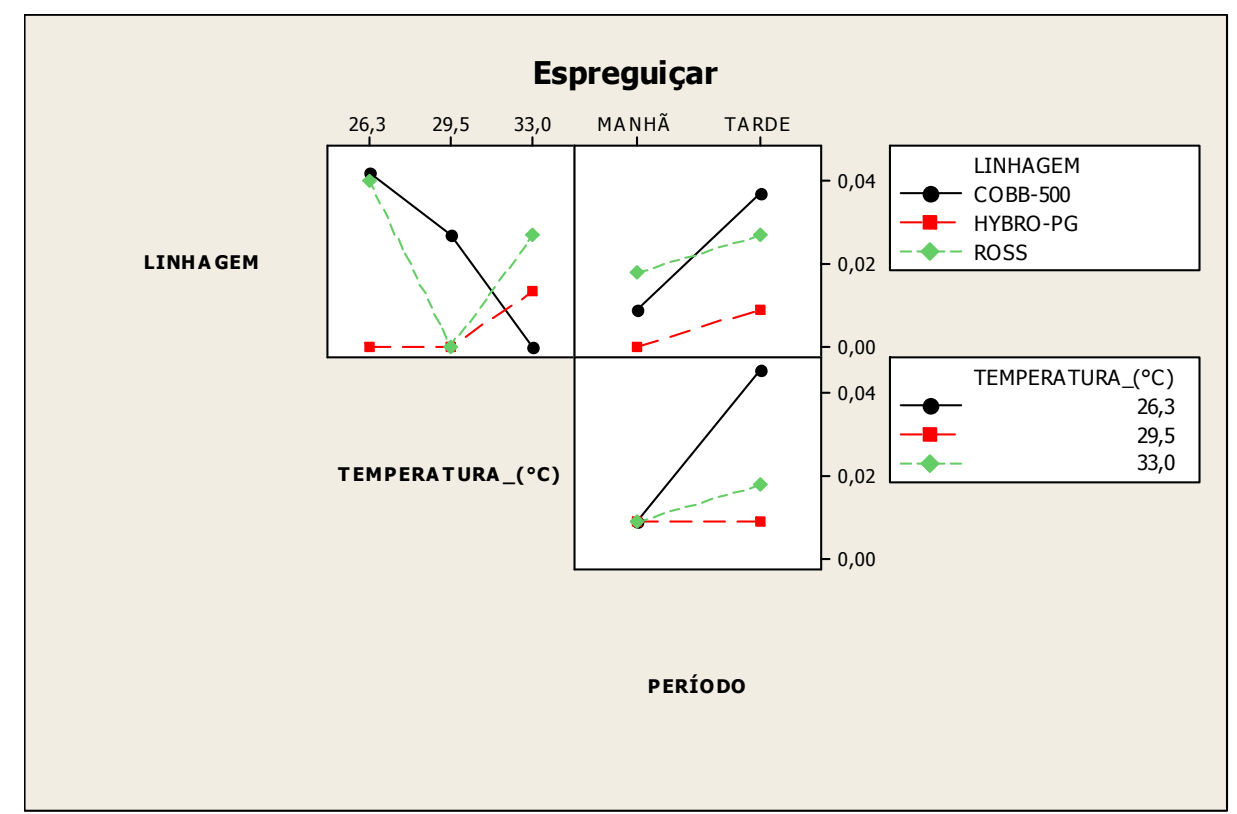

FIGURA 13. Interações entre linhagem, temperatura e período, duas a duas, perante a frequiência de ocorrência do comportamento "espreguiçar". 


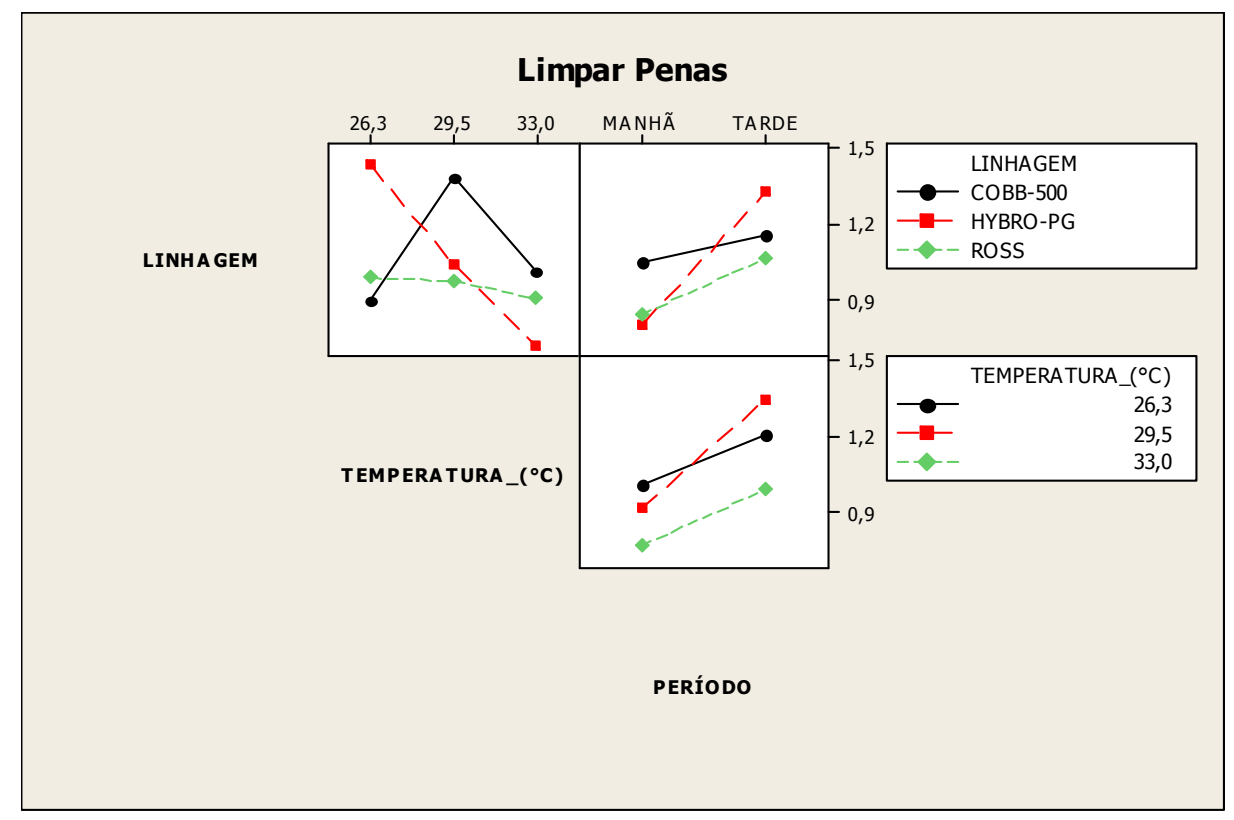

FIGURA 14. Interações entre linhagem, temperatura e período, duas a duas, perante a frequiência de ocorrência do comportamento "espreguiçar".

Na Figura 15, observa-se que os tempos médios de expressão de limpar penas é inversamente proporcional à freqüência do mesmo comportamento, quando a interação linhagem e temperatura é comparada com a Figura 14. Não se observa interação entre os fatores linhagem e período no tempo de expressão de limpar penas, e verifica-se, na interação dos fatores temperatura e período, que o tempo médio de expressão desse comportamento foi diferente apenas para a temperatura de $26,3{ }^{\circ} \mathrm{C}$, na qual se observa decréscimo do tempo de expressão à tarde.

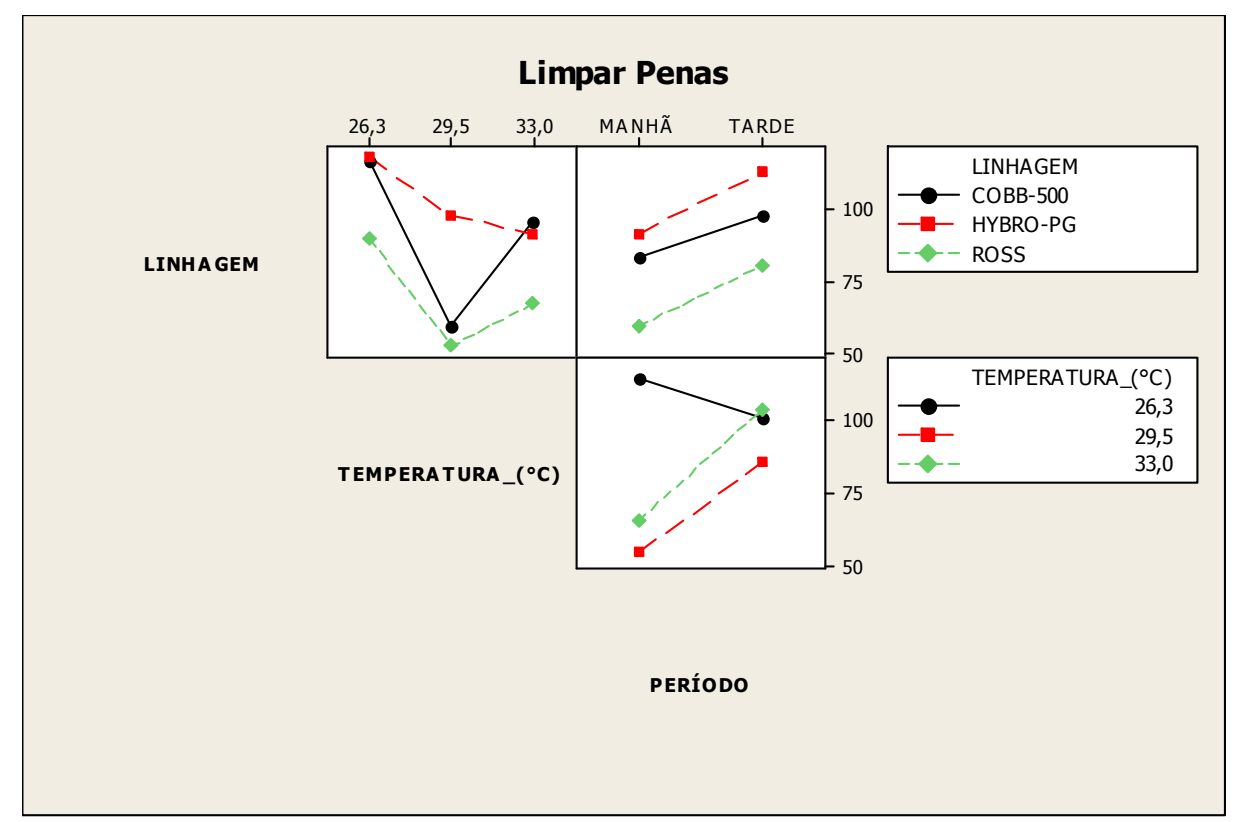

FIGURA 15. Interações entre linhagem, temperatura e período, duas a duas, perante a média do tempo de expressão do comportamento "limpar penas".

O tempo de permanência no ninho apresentou interações entre todos os fatores tomados dois a dois, conforme se verifica na Figura 17. Esses resultados denotam a complexidade com que as variáveis do ambiente atuam nesse comportamento para cada linhagem. Já na frequiência de visitas ao local (Figura 16), não se verifica interação entre os fatores linhagem e período, na qual se pode 
afirmar que todas as linhagens tendem a visitar mais o ninho no período da manhã, e para os demais fatores tomados dois a dois, não se verificam interações importantes na Figura 17.

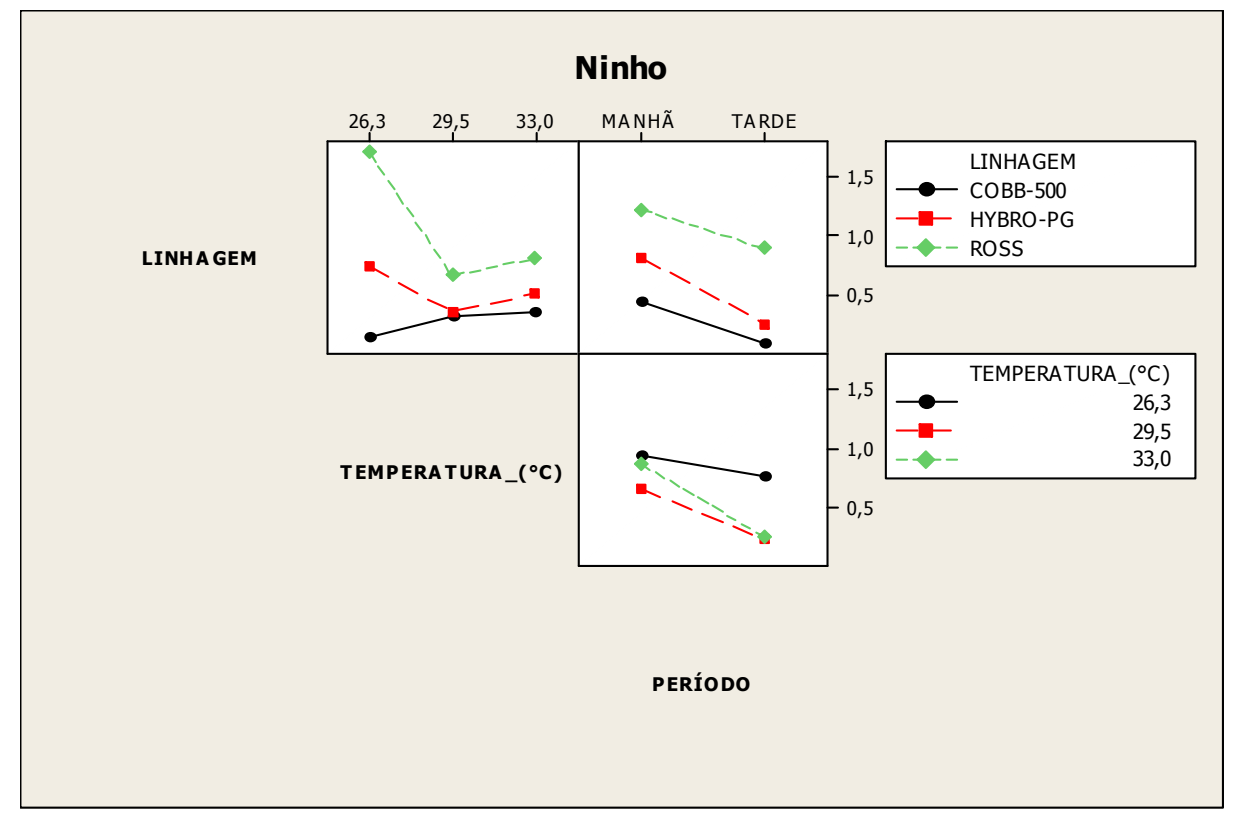

FIGURA 16. Interações entre linhagem, temperatura e período, duas a duas, perante a frequiência de visitas ao "ninho".

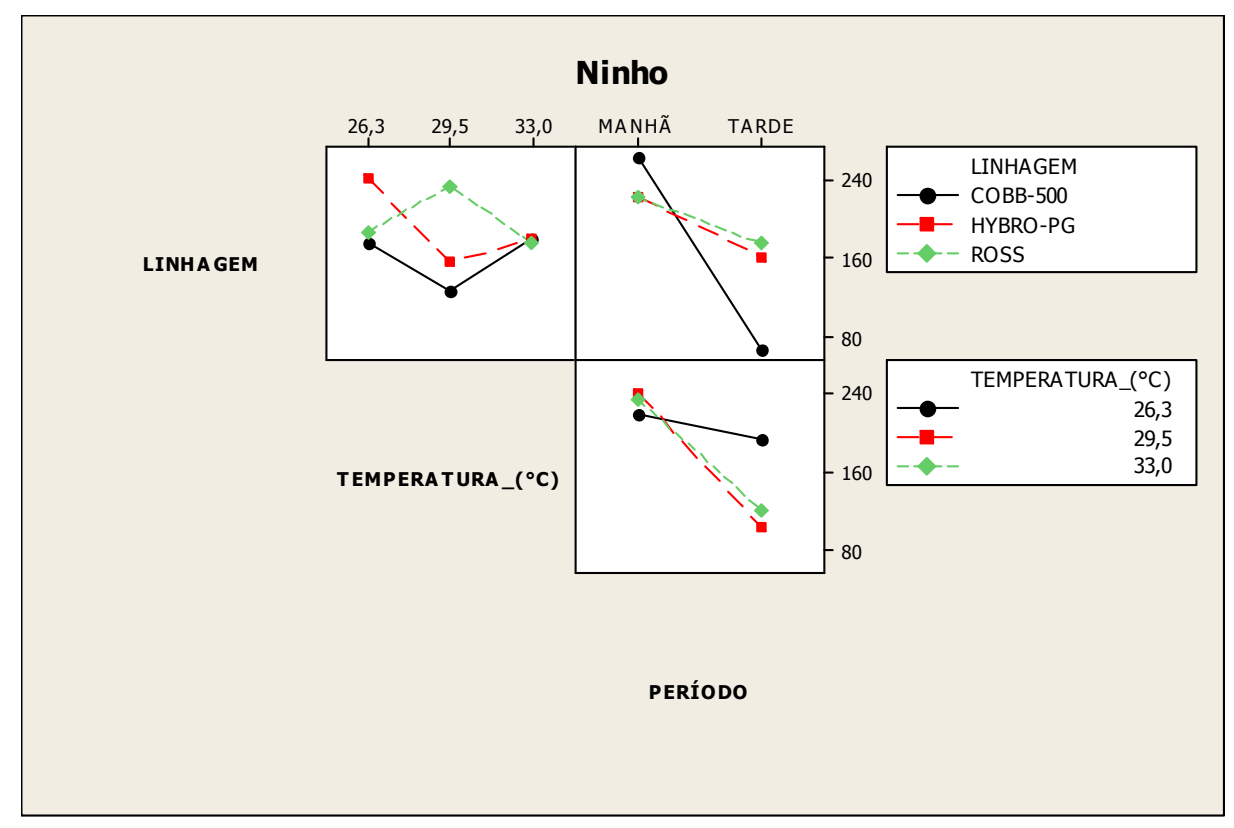

FIGURA 17. Interações entre linhagem, temperatura e período, duas a duas, perante a média do tempo de permanência no "ninho".

Das análises mostradas acima, verificaram-se interações entre a temperatura e a linhagem nas frequiências e nos tempos médios observados de todos os comportamentos, conforme mostrados na Tabela 2. Nessa tabela, as freqüências observadas dos comportamentos abrir asas, ciscar, espreguiçar e limpar penas, e os tempos médios de expressão dos comportamentos beber água e permanência no ninho mostraram interações significativas entre todos os fatores experimentais tomados dois a dois. Esses resultados corroboram os relatos de KEER-KEER et al. (1996), McGARY et al. (2003) e CHENG \& MUIR (2005), que também observaram diferenças importantes nos comportamentos quando comparados entre linhagens. 
TABELA 2. Interações entre os fatores experimentais significativas para $\alpha=5 \%$ para cada comportamento.

\begin{tabular}{ccccc}
\hline Medida & Comportamento & Linhagem*Temperatura & Linhagem*Período & Temperatura*Período \\
\hline freq. & beber água & $\mathrm{X}$ & $\mathrm{X}$ & $\mathrm{X}$ \\
\hline tempo & beber água & $\mathrm{X}$ & $\mathrm{X}$ & $\mathrm{X}$ \\
\hline freq. & arrepiar penas & $\mathrm{X}$ & $\mathrm{X}$ & $\mathrm{X}$ \\
\hline freq. & abrir asas & $\mathrm{X}$ & $\mathrm{X}$ & $\mathrm{X}$ \\
\hline freq. & ciscar & $\mathrm{X}$ & $\mathrm{X}$ & \\
\hline tempo & ciscar & $\mathrm{X}$ & $\mathrm{X}$ & $\mathrm{X}$ \\
\hline freq. & deitar & $\mathrm{X}$ & & $\mathrm{X}$ \\
\hline tempo & deitar & $\mathrm{X}$ & & $\mathrm{X}$ \\
\hline freq. & bebedouro & $\mathrm{X}$ & $\mathrm{X}$ & $\mathrm{X}$ \\
\hline tempo & bebedouro & $\mathrm{X}$ & $\mathrm{X}$ & $\mathrm{X}$ \\
\hline freq. & espreguiçar & $\mathrm{X}$ & & $\mathrm{X}$ \\
\hline freq. & limpar penas & $\mathrm{X}$ & $\mathrm{X}$ & \\
\hline tempo & limpar penas & $\mathrm{X}$ & $\mathrm{X}$ & \\
\hline freq. & ninho & $\mathrm{X}$ & & \\
\hline tempo & ninho & & & \\
\hline
\end{tabular}

Entre as variáveis temperatura e período, verificaram-se interações em quase todos os comportamentos, com exceção dos comportamentos freqüência de deitar e tempos de permanência no bebedouro e no ninho. Essas interações corroboram os relatos de PETTIT-RILEY \& ESTEVEZ (2001), PETTIT-RILEY et al. (2002) e ESTEVEZ et al. (2003). Esses autores observaram diferença na frequiência de ocorrências dos comportamentos na presença do alimento (manhã), comparada com a ausência desse (tarde), em aves submetidas a regime de restrição alimentar.

\section{CONCLUSÕES}

Observaram-se interações entre os fatores experimentais nas freqüências de ocorrências e tempos de expressão dos comportamentos observados, confirmando a hipótese de que esses fatores agem complexamente no bem-estar das matrizes pesadas. Houve diferenças significativas entre as tendências nas expressões dos comportamentos expressos pelas linhagens Cobb-500, Hybro-PG e Ross-308, confirmando a hipótese de que as linhagens reagem de maneira diferente ao ambiente de criação. Essas conclusões reforçam a necessidade do monitoramento em tempo das matrizes pesadas em alojamentos comerciais, dada a complexidade com que as variáveis do ambiente afetam o bem-estar. A pesquisa permitiu concluir que a avaliação do bem-estar de matrizes pesadas submetidas à restrição alimentar, baseada no comportamento, deve considerar o período do dia para as observações dos comportamentos, pois a presença do alimento no período da manhã afetou significativamente as freqüências e os tempos de expressão dos comportamentos.

\section{REFERÊNCIAS}

BIZERAY, D.; ESTEVEZ, I.; LETERRIER, C.; FAURE, F.M. Effects of increasing environmental complexity on the physical activity of broiler chickens. Applied Animal Behaviour Science, Sweden, v.79, n.1, p.27-41, 2002.

CAMPOS, E.J. O comportamento das aves. Revista Brasileira de Ciência Avícola, Campinas, v.2, n.2, p.93-113, 2000.

CHENG, H.; MUIR, W.M. The effects of genetic selection for survivability and productivity on chicken physiological homeostasis. World's Poultry Science Journal, Beekbergen, v.61, n.3, p.38398, 2005. 
DUNCAN, I.J.H.; MENCH, J.A. Behaviour as an indicator of welfare in various systems. In: EUROPEAN SYMPOSIUM ON POULTRY WELFARE, 4., 1993, Potters Bar. Proceedings... Potters Bar: Universities Federation for Animal Welfare, 1993. p.69-80.

ESTEVEZ, I.; KEELING, L.J.; NEWBERRY, R.C. Decreasing aggression with increasing group size in young domestic fowl. Applied Animal Behaviour Science, v.84, p.213-218, 2003.

KEER-KEER, S.; HUGHES, B.O.; HOCKING, P.M.; JONES, R.B. Behavioural comparison of layer and broiler fowl: measuring fear responses. Applied Animal Behaviour Science, Linköping, v.49, p.321-333,1996.

MACARI, M.; FURLAN, R.L.; MAIORKA, A. Aspectos fisiológicos e de manejo para manutenção da homeostase térmica e controle de síndromes metabólicas. In: MENDES, A.A.; NÄÄS, I.A.; MACARI, M. Produção de frangos de corte. Campinas: FACTA, 2004. p.137-55.

MARCHANT, J.A.; ANDERSEN, H.J.; ONYANGO, C.M. Evaluation of an imaging sensor for detecting vegetation using different waveband combinations. Computers and Eletronics in Agriculture, Illinois, v.32, p.101-17, 2001.

MARÍA, G.A.; ESCÓS, J.; ALADOS, C.L. Complexity of behavioural sequences and their relation to stress conditions in chickens (Gallus gallus domesticus): a non-invasive technique to evaluate animal welfare. Applied Animal Behaviour Science, Linköping, v.86, p.93-104, 2004.

McGARY, S.; ESTEVEZ, I.; RUSSEK-COHEN, E. Reproductive and agressive behaviour in male broiler breeders with varying fertility levels. Applied Animal Behaviour Science, Linköping, v.82, p.29-44, 2003.

PEREIRA, D.F. Avaliação do comportamento individual de matrizes pesadas (frango de corte) em função do ambiente e identificação da temperatura crítica máxima. 2003. 174 f. Dissertação (Mestrado em Construções Rurais) - Faculdade de Engenharia Agrícola, Universidade Estadual de Campinas, Campinas, 2003.

PETTIT-RILEY, R.; ESTEVEZ, I.; RUSSEK-COHEN, E. Effects of crowding and access to perches on aggressive behaviour in broiler. Applied Animal Behaviour Science, Linköping, v.79, p.11-25, 2002.

PETTIT-RILEY, R.; ESTEVEZ, I. Effects of density on perching behaviour of broiler chickens. Applied Animal Behaviour Science, Linköping, v.71, p.127-40, 2001. 